University of Windsor

Scholarship at UWindsor

2006

\title{
Cathepsin B localizes to plasma membrane caveolae of differentiating myoblasts and is secreted in an active form at physiological $\mathrm{pH}$
}

\author{
Derek T. Jane \\ University of Windsor \\ Les Morvay \\ University of Windsor \\ Luis DaSilva \\ University of Windsor \\ Dora Cavallo-Medved \\ University of Windsor \\ Bonnie F. Sloane
}

See next page for additional authors

Follow this and additional works at: https://scholar.uwindsor.ca/biologypub

Part of the Biology Commons

\section{Recommended Citation}

Jane, Derek T.; Morvay, Les; DaSilva, Luis; Cavallo-Medved, Dora; Sloane, Bonnie F.; and Dufresne, Michael J., "Cathepsin B localizes to plasma membrane caveolae of differentiating myoblasts and is secreted in an active form at physiological pH" (2006). Biological Chemistry, 387, 2, 223-234.

https://scholar.uwindsor.ca/biologypub/27

This Article is brought to you for free and open access by the Department of Biological Sciences at Scholarship at UWindsor. It has been accepted for inclusion in Biological Sciences Publications by an authorized administrator of Scholarship at UWindsor. For more information, please contact scholarship@uwindsor.ca. 


\section{Authors}

Derek T. Jane, Les Morvay, Luis DaSilva, Dora Cavallo-Medved, Bonnie F. Sloane, and Michael J. Dufresne 


\section{Cathepsin B localizes to plasma membrane caveolae of differentiating myoblasts and is secreted in an active form at physiological pH}

\author{
Derek T. Jane1, Les Morvay', Luis DaSilva1, \\ Dora Cavallo-Medved², Bonnie F. Sloane ${ }^{2}$ and \\ Michael J. Dufresne, ${ }^{1, *}$ \\ ${ }^{1}$ Biological Sciences, University of Windsor, Windsor \\ N9B 3P4, ON, Canada \\ 2 Department of Pharmacology, Wayne State University, \\ Detroit, MI 48201, USA \\ ${ }^{*}$ Corresponding author \\ e-mail: duf1@uwindsor.ca
}

\begin{abstract}
Our in vitro studies support a functional link between the induction of cathepsin B gene expression and the catabolic restructuring associated with myotube formation during myogenesis in vivo. We have tested two predictions that are basic to this hypothesis: (1) that active cathepsin B is localized to plasma membrane caveolae of fusing myoblasts; and (2) that active cathepsin B is secreted from fusing myoblasts at physiological $\mathrm{pH}$. During differentiation, L6 rat myoblasts demonstrated a fusion-related increase in activity associated with the 25/26-kDa, fully processed, active form of cathepsin B. Immunocytochemical studies demonstrated a redistribution of lysosomal cathepsin B protein toward the membrane of fusing myoblasts, and a colocalization of cathepsin B with caveolin-3, the muscle-specific structural protein of membrane caveolae. Sucrose density fractionation and Western blot analysis demonstrated that an active form of cathepsin B localizes to caveolar fractions along with caveolin-3, annexin-VII, $\beta$-dystroglycan and dystrophin. Finally, 'real-time' activity assays and Western blot analysis demonstrated that active cathepsin B is secreted from fusing myoblasts at physiological $\mathrm{pH}$. Collectively, these studies support an association of active cathepsin B with plasma membrane caveolae and the secretion of active cathepsin B from differentiating myoblasts during myoblast fusion.
\end{abstract}

Keywords: cathepsin B; caveolae; membrane; myogenesis; myotubes.

\section{Introduction}

The formation of non-cycling, multinucleated myotubes from cycling, mononucleated skeletal-muscle myoblasts (myogenesis) is accompanied by dramatic changes in gene expression and cell physiology (Yeoh and Holtzer, 1977; Stockdale, 1992). It is well established that myotube formation involves recognition events that allow committed myoblasts to align and adhere after migration, and fusion events that allow adherent myoblasts to fuse with each other (Dufresne et al., 1976). The recognition events appear to be mediated by alterations in cell membrane glycoproteins (Knudsen and Horwitz, 1977), whereas the fusion events appear to be mediated by extensive reorganization of membrane components to form protein-free areas of phospholipids (Thiery et al., 1982; Rieger et al., 1985).

There is longstanding evidence that many cellular proteases are involved in the structural alterations associated with recognition and fusion events, and that the expression of these proteases is tightly regulated during myogenesis (Kaur and Sanwal, 1981; Guerin and Holland, 1995; Dourdin et al., 1999). Our studies in rat, mouse, and human myoblasts in culture suggest that the lysosomal cysteine protease, cathepsin B (catB), is one these cellular proteases. For example, we have demonstrated that a fusion-related increase in catB activity occurs in fusion-capable L6 rat skeletal muscle myoblasts, but not in fusion-deficient L6 variants or in muscle fibroblasts (Jane and Dufresne, 1994). Moreover, reductions in catB gene expression in gene-trapped $\mathrm{C} 2 \mathrm{C} 12$ mouse myoblasts or of catB activity in CA074Me-treated L6 rat myoblasts (Jane et al., 2002a,b) are reversibly associated with reductions in the size and extent of myotube formation over time. While these results support a functional link between the regulated expression of catB and myoblast fusion, little is known about the precise cellular locations and mechanisms associated with catB function. Studies demonstrating an association between caveolin-1 (cav-1), the principle component of caveolae (Anderson, 1998), and catB at the level of the plasma membrane may provide an important clue. These studies suggest that tumor progression is mediated in part by the association of catB with cav-1 in membrane caveolae of tumor cells (Cavallo-Medved et al., 2003, 2005), and the subsequent activation of a proteolytic cascade consisting of remodeling proteases such as matrix metalloproteases, plasminogen and tissue-type plasminogen activator (Cavallo-Medved et al., 2005).

The principle component of skeletal muscle membrane caveolae is the integral membrane protein caveolin-3 (cav-3; Song et al., 1996). Cav-3 is expressed only in fusing myoblasts and plays a key role in the organization and stabilization of the dystrophin-glycoprotein complex (DGC), which in turn serves as a link between laminin in the extracellular matrix (ECM) and the F-actin cytoskeleton (Meacci et al., 2000). Since both catB and cav-3 are up-regulated during myogenesis by the MyoD family of skeletal muscle-specific transcription factors (Biederer et al., 2000; Jane et al., 2002c), we hypothesize that a caveolae-associated proteolytic cascade similar to that hypothesized in tumor cells is one of the mechanisms 
mediating the extensive cell-membrane, membranecytoskeleton modifications required for myoblast-myoblast fusion. We further hypothesize that active catB on the membrane of and secreted from fusing myoblasts participates in the extensive cell surface-ECM modifications required for myotube formation (Adams and Watt, 1993). Two predictions are basic to these hypotheses: (1) that catB localizes to plasma membrane caveolae of differentiating myoblasts; and (2) that active catB is localized on and secreted from fusing myoblasts at physiological $\mathrm{pH}$. These predictions were examined in the current study using cell fractionation, Western blot, immunocytochemical, and 'real-time' catB activity analyses in cell-free, whole and living L6 myoblast preparations.

\section{Results}

\section{Levels of the 25/26-kDa active form of cathepsin B} increase during myogenesis

There are literally thousands of non-specific and musclespecific genes, the expression of which is regulated during myoblast differentiation (Gogos et al., 1996). The expression of many of these, including the two classic biochemical markers of terminal differentiation, creatine phosphokinase (CPK) activity and myosin heavy chain (MHC) protein (Figure 1), is temporally related to the fusion process (Dufresne et al., 1976; Jane and Dufresne, 1994) and involves the MyoD family of muscle-specific transcription factors (Olson, 1990). Our previous (Jane and Dufresne, 1994; Jane et al., 2002a,b,c) and current studies in myoblast cell cultures suggest that catB belongs to this latter class of genes (Figure 1). While catB is expressed at constitutively high levels in most cell types throughout growth (Gong et al., 1993), levels of catB activity in differentiating myoblasts decreased as dividing presumptive myoblasts became post-mitotic (day 4) and then increased as myotube formation proceeded (days 5-6). The difference in catB activities between days of differentiation was significant $(p<0.001)$.

There are two mature active forms of catB, a singlechain form and a lower-molecular-mass, fully processed double-chain form. The extent to which the inactive proform of catB is processed to either of these active forms varies between cell types within and among species (Mach et al., 1992). A monospecific antibody to catB that recognizes all forms of the protein (i.e., Western blots) was used to determine whether fusion-related alterations in catB activity were accompanied by alterations in the relative contribution of these two active forms (Figure 2). Reproducible changes were observed. Specifically, as proliferating myoblasts (i.e., days 2 and 3 ) became postmitotic (i.e., day 4) the expression level of the $31-\mathrm{kDa}$ single-chain form of catB decreased by approximately two-fold. These lower levels were maintained as myoblasts fused to form myotubes (i.e., days 5 and 6). In contrast, low levels of the 25/26-kDa mature doublechain form of catB were first detected in day- 3 cells, then increased as myotube formation proceeded (Figure 2B). When the band intensity of each of the two active catB forms was quantified and summed for each day (Figure

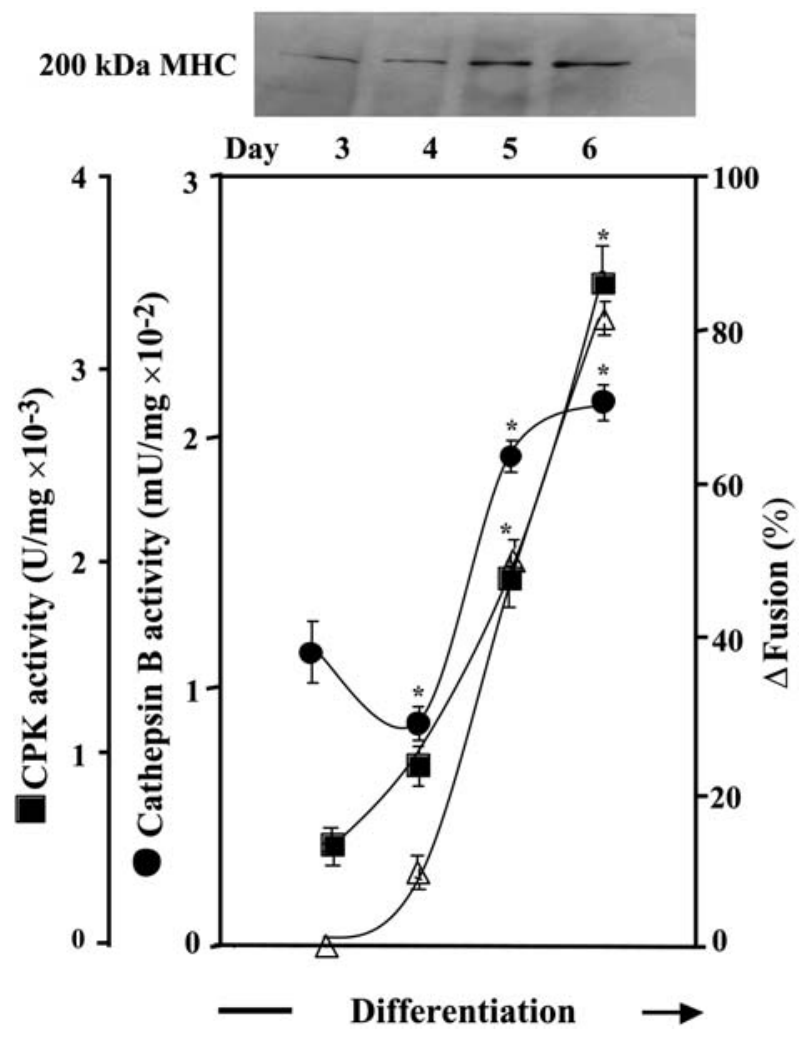

Figure 1 Expression of myogenic phenotypes and cathepsin B activity analyses.

For each day, beginning on day 3 , the percentage fusion (triangles) was determined and cells were collected and homogenized. Percentage fusion is defined as: (number of nuclei within myotubes divided by total number of nuclei within a microscopic field) $\times 100$. At least 10 fields were examined. cat $B$ activity (circles) was measured in cell homogenates using the selective substrate Z-Arg-Arg-NHMec and confirmed using the selective catB inhibitor CA074. catB activity is expressed as $\mathrm{mU} / \mathrm{mg}$ protein, where $1 \mathrm{mU}$ is defined as the amount of protease that liberates $1 \mathrm{nmol}$ of aminomethylcoumarin per minute. Creatine phosphokinase activity (CPK) activity (squares) was measured using ADP-glutathione according to the Sigma diagnostics kit. CPK activity is expressed as units ( $\mathrm{nmol} / \mathrm{min}$ ) per $\mathrm{mg}$ according to a standard absorbance curve for the creatine product. For catB and CPK activity assays, each value represents the mean of at least three measurements $(n=3)$, with error bars denoting the standard error. The differences in activities between successive stages were statistically significant $\left({ }^{*} p<0.001\right)$. Myosin heavy chain (MHC) expression was measured by Western blot analysis using a monoclonal antibody specific to myosin heavy chain. Three successive stages of myoblast differentiation are represented: (i) division of presumptive myoblasts (day 3); (ii) alignment and adherence of postmitotic myoblasts (day 4); and (iii) fusion of non-cycling postmitotic myoblasts to form myotubes (days 5-6).

$2 \mathrm{~B})$, the pattern of total catB protein corresponded with that for catB activity (compare Figure $2 \mathrm{~B}$ and Figure 1). These transient expression patterns were reproducible between experiments $(n=3)$.

\section{Cathepsin B protein relocalizes toward the plasma membrane of fusing myoblasts}

It is generally agreed that the formation of myotubes requires dramatic structural reorganization of the cytoskeleton, plasma membrane and ECM associated with 
$\mathbf{A}$

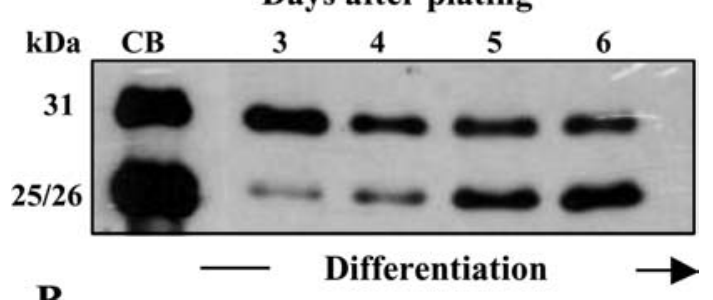

B

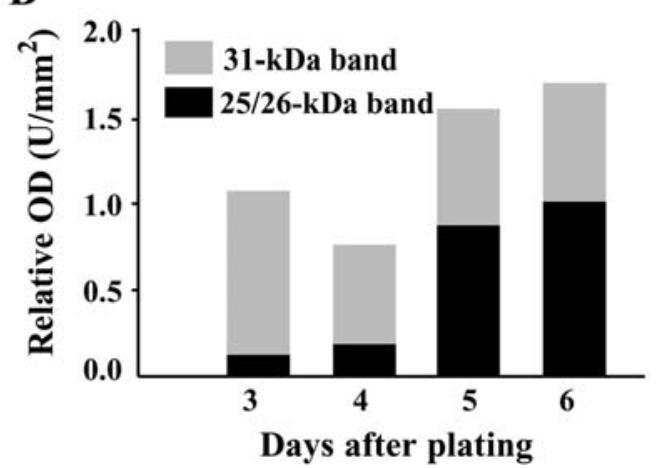

Figure 2 Cathepsin B Western blot analyses.

(A) For each of three independent experiments, equal amounts of protein from myoblast homogenates were used for immunoblot analysis using a rabbit anti-human liver catB monospecific antibody, and enhanced chemiluminescence as described in the materials and methods section. The catB marker lane was loaded with purified human liver catB (CB). Experimental lanes were loaded with $8 \mu \mathrm{g}$ of protein from cells on days 3-6. Standards were used to determine the molecular mass range $(\mathrm{kDa})$ of purified human catB (indicated on the left). After transfer, gels were stained with Coomassie Blue and bands corresponding to constitutively expressed proteins were analyzed to ensure equal loading. Immunoblots are representative of at least three experiments. (B) Densitometric analysis of the 31-kDa (gray bar) and the $25 / 26-k D a$ (black bar) forms of catB was performed on scanned images of Western blots exposed to hyperfilm for $30 \mathrm{~s}$ using a Fuji imaging system and are presented as relative optical density in arbitrary units per $\mathrm{mm}^{2}\left(\mathrm{AU} / \mathrm{mm}^{2}\right)$. The intensity of each band is expressed relative to the optical density of the darkest band. For each day, the 25/26-kDa and 31-kDa bands were summed to provide the total level of catB protein detected.

each myoblast (Knudsen and Horwitz, 1977; Thiery et al., 1982; Adams and Watt, 1993). These structural changes coincide with a redistribution of lysosomal vesicles within the cytoplasm of differentiating myoblasts (Bird et al., 1981). In view of this consensus, it is reasonable to predict that increased levels of catB during myogenesis are associated with a redistribution of catB protein from its perinuclear site of synthesis on polysomes of the rough endoplasmic reticulum (Berquin and Sloane, 1996) toward the membrane of fusion-committed myoblasts via lysosomal vesicles. We used a LysoTracker probe (Invitrogen, Burlington, Canada), which is highly selective for acidic organelles, for immunocytochemistry and confocal image analysis to examine this prediction (Figure 3).

In proliferating myoblast populations, LysoTrackerstained acidic vesicles appeared punctate and were localized close to the nucleus (i.e., perinuclear) (Figure 3, upper panels). Stained acidic vesicles in post-mitotic and fusing populations were also punctate (Figure 3); however, they appeared to be redistributed throughout the cell and toward the plasma membrane. This redistribution pattern was similar to that observed in whole cell preparations of presumptive, postmitotic, and fused populations of $\mathrm{L} 6$ myoblasts stained for intracellular catB using primary antibodies specific to catB and the cytoskeleton protein tubulin, and the appropriate secondary antibody conjugated to fluorescein isothiocyanate (FITC) and Texas red, respectively (Figure 3, lower panels). CatB staining was punctate and concentrated in the perinuclear region of dividing presumptive myoblasts. However, when these myoblasts became aligned and began to form myotubes, catB staining was redistributed throughout the cell and toward the plasma membrane. The staining in the largest myotubes appeared to be diffuse and less intense than the staining patterns in the early stages of fusion. This redistribution pattern was not observed during growth of fusion-deficient myoblasts or muscle fibroblasts (data not shown).

More direct evidence for the localization of catB to the membrane of fusing myoblasts was obtained by double staining for catB and cav-3 (Figure 4). Cav-3 is expressed in fusing but not pre-fusion populations of myoblasts (see Figure 5) and is the structural component of plasma membrane caveolae of terminally differentiating skeletal myoblasts (Lisanti et al., 1994). In individual scans for each protein, cav-3 (red stain) and catB (green stain) were localized throughout the cell and at the level of the plasma membrane of fusing myoblasts (Figure 4). When these scans were merged, areas of overlap for cav-3 and catB (i.e., yellow staining) were concentrated in regions adjacent to the cytoplasmic face of the cell membrane.

\section{Cathepsin B co-fractionates with caveolae- associated proteins}

Caveolae, invaginations of the plasma membrane, play a role in many cellular membrane activities, including receptor-mediated uptake, transcytosis, stabilization of lipid rafts, and compartmentalization of signaling events at the cell surface (Anderson, 1998). Recent studies have demonstrated that catB associates with the structural protein cav-1 in plasma membrane caveolae of human colorectal carcinoma cells, and suggested that this association is implicated in proteolytic remodeling associated with tumor progression (Cavallo-Medved et al., 2003, 2005). In view of these studies and our whole-cell studies demonstrating colocalization of catB and cav-3 in terminally differentiated myoblasts, we examined the association of catB with membrane caveolae and their associated proteins isolated from differentiating populations of L6 myoblasts using a well-established protocol based on the insolubility of caveolae to Triton-X 100 extraction and their buoyant density in equilibrium sucrose gradients (Lisanti et al., 1994). Fractions (1.0 ml) were analyzed by immunoblotting for catB, and the caveolae-associated proteins cav-3, annexin VII, dystrophin, and $\beta$-dystroglycan (Figure 5).

For proliferating myoblasts (Figure 5, left panels), a $31-\mathrm{kDa}$ form of catB was detected in fractions 7-9 containing the lysosomal marker protein, $\beta$-galactosidase (Cavallo-Medved et al., 2003). This is consistent with the localization of the $31-\mathrm{kDa}$ form of active catB protein in both whole-cell (see Figure 2) and lysosomal fractions of 
A
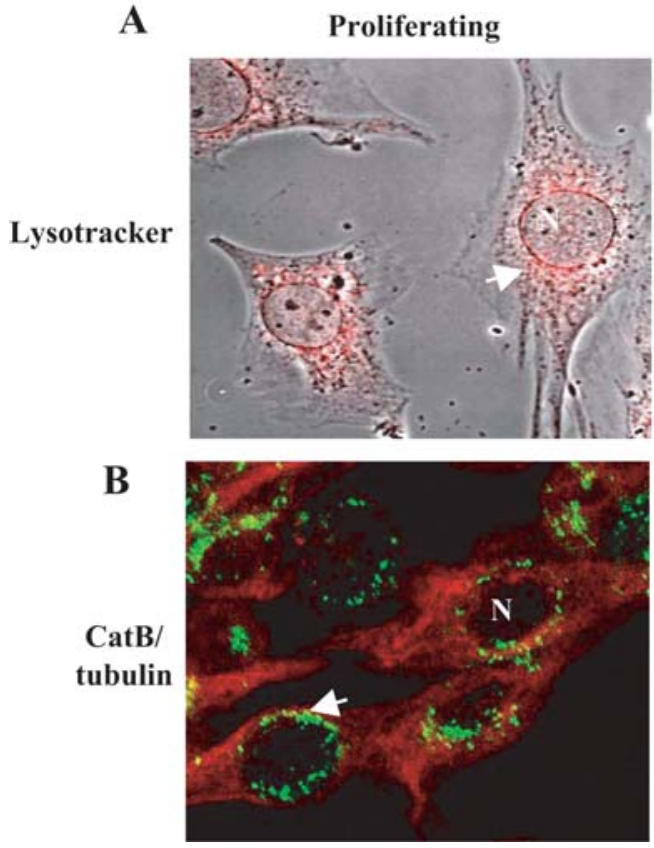
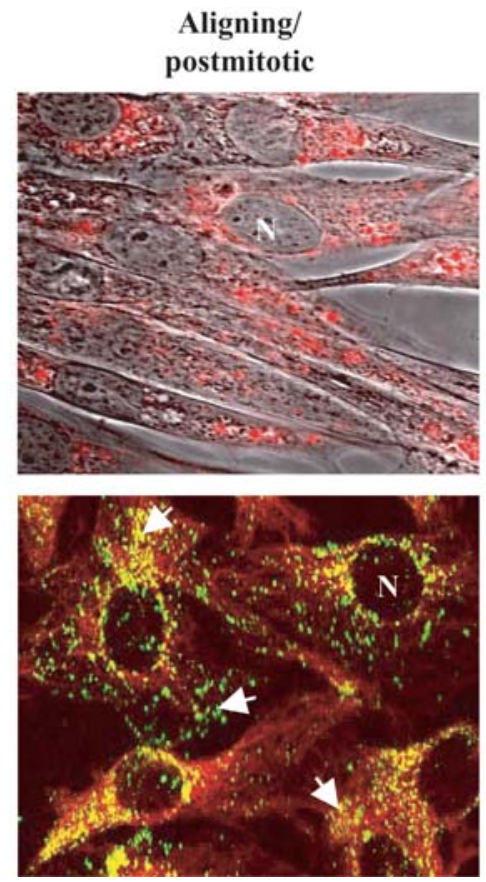

Fusing
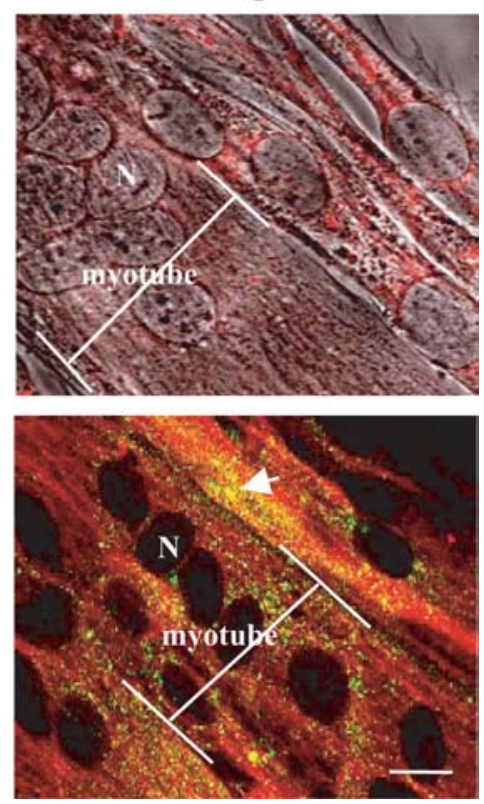

Figure 3 Immunocytochemical localization of lysosomes and cathepsin B within differentiating L6 myoblasts.

(A) For live-cell staining of lysosomes, proliferating, postmitotic, and fusing myoblasts were rinsed with HBSS and LysoTrackersupplemented serum-free medium was added. After $2.5 \mathrm{~h}$ of incubation, the medium was removed and the LysoTracker was 'chased' for $1 \mathrm{~h}$ in $10 \%$ supplemented horse serum medium. Lysosomal staining of living cells was observed using a Zeiss LSM microscope fitted with a $40 \times$ immersion lense (see materials and methods). (B) For fixed cell catB/tubulin staining, proliferating, postmitotic, and fusing myoblasts were fixed and stained for: (1) catB protein using rabbit anti-human liver catB IgG as primary antibody and FITCconjugated donkey anti-rabbit IgG as secondary antibody; and (2) tubulin using mouse anti-tubulin IgG as primary antibody and Texas red-conjugated donkey anti-mouse IgG as secondary antibody. Intracellular staining was observed with a Zeiss LSM 310 microscope in confocal mode at an original magnification of $630 \times$ under oil immersion (see materials and methods). For all staining, images are representative of three experiments. Bar: $20 \mu \mathrm{m}$.

crude myoblast cell lysates (data not shown). Cav-3 protein was not detected in any of the fractions analyzed, a result consistent with the fact that cav- 3 is not expressed in proliferating myoblasts (Biederer et al., 2000). In contrast, low levels of the 47-kDa isoform of annexin VII were detected in all subcellular fractions, a result consistent with its reported basal-level expression in proliferating myoblast populations (Clemen et al., 1999). A 116-kDa form of dystrophin was detected in the dense cytosolic fractions $6-9$, while a $43-k D a$ form of $\beta$-dystroglycan was detected in light membrane fractions 4 and 5. These results are consistent with differential expression of dystrophin and its associated proteins in myoblast cell culture (Radojevic et al., 2000; Blake et al., 2002).

For fusing myoblasts (Figure 5, right panels), the $25 / 26-k D a$ form of active catB protein was detected in the same fractions as cav- 3 (light density fractions 4 and 5). This result is consistent with the detection of the 25/26-kDa fully processed form of active catB protein in whole cells (Figure 2) prepared from fusing myoblast
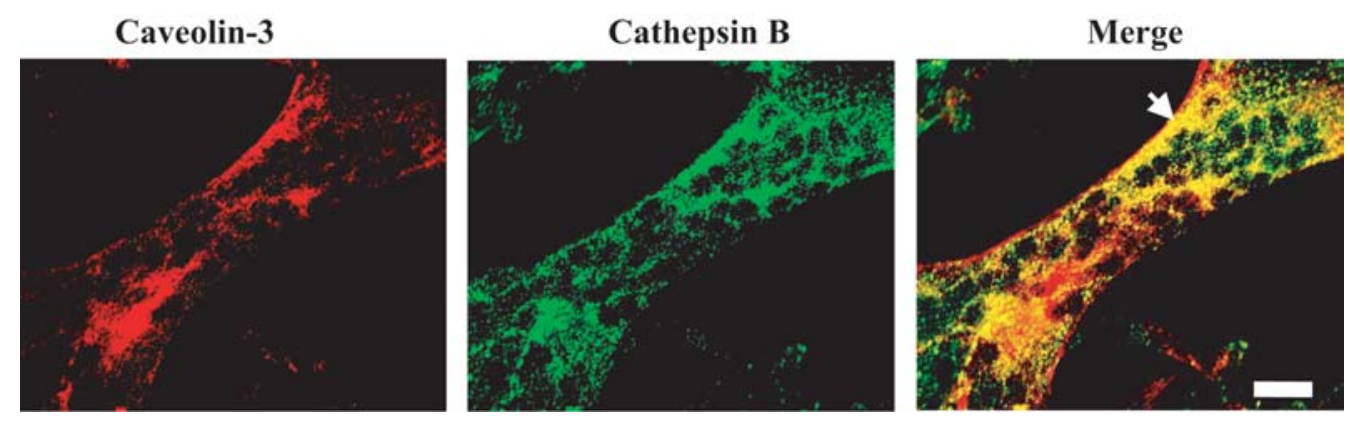

Figure 4 Immunocytochemical localization of cathepsin B and caveolin-3 within differentiating L6 myoblasts.

For fixed-cell catB/cav-3 double staining, fusing myoblasts were fixed and stained for: (1) catB protein using rabbit anti-human liver catB IgG as primary antibody and FITC-conjugated donkey anti-rabbit IgG as secondary antibody; and (2) caveolin-3 using mouse anti-caveolin-3 IgG as primary antibody and Texas red-conjugated donkey anti-mouse lgG as secondary antibody (see materials and methods). Staining was observed using a Zeiss LSM 310 microscope in confocal mode at an original magnification of $630 \times$ under oil immersion. Intracellular immunostaining for cav-3 and catB is shown in red and green, respectively. The arrow points to overlap for cav-3 and catB staining, shown in yellow adjacent to the cytoplasmic face of the cell membrane. For all staining, images are representative of three experiments. Bar: $20 \mu \mathrm{m}$. 


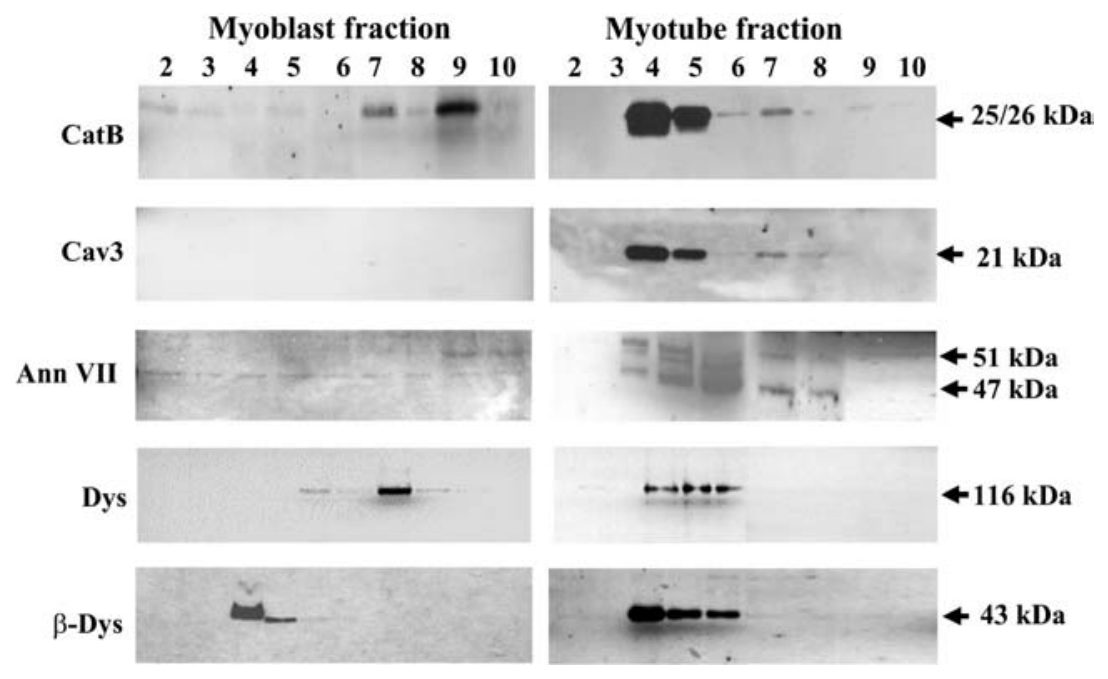

Figure 5 Western blot analyses of myoblast and myotube sucrose density fractions.

Equal amounts of protein from cellular lysates of proliferating and fusing myoblasts were fractionated in discontinuous $5-40 \%$ sucrose density gradients as described in the materials and methods section. Fractions were collected from the top of the gradient and equalvolume aliquots were analyzed by SDS-PAGE and immunoblotting. Panels from top to bottom represent fractions 2-10 analyzed for catB, caveolin-3 (Cav-3), annexin IIV (Ann IIV), dystrophin (dys), and $\beta$-dystroglycan ( $\beta$-Dys) immunoreactivity, respectively, using mono- or polyclonal antibodies and enhanced chemiluminescence as described in materials and methods. Standards were used to determine the molecular mass of proteins bands $(\mathrm{kDa})$. Immunoblots are representative of at least three experiments.

lysates. Light density fractions 4-6 contained the following caveolae-associated proteins: (a) the 47- and 51-kDa isoforms of annexin VII; (b) 116-kDa dystrophin; and (c) the $43-k D a$ form of $\beta$-dystroglycan.

\section{Active cathepsin B is localized on and secreted from differentiating myoblasts}

Our cell-free and whole-cell analyses suggest that the $25 / 26-k D a$ fully processed form of active catB is localized to the cytoplasmic face of the plasma membrane within caveolae of differentiating rat myoblasts. These results support the prediction that active catB plays a role in the extensive cell membrane-cytoskeletal rearrangements required for myoblast fusion. However, myoblast fusion also requires extensive cell surface-ECM modification (Adams and Watt, 1993). While a role for catB in this modification is hypothetical, it has been suggested that catB localized to the cell surface, and secreted from tumor cells, degrades ECM components during tumor invasion (Sameni et al., 2000; Sloane et al., 2005). In view of these considerations, it is also reasonable to predict that: (1) CatB is localized on the extracellular surface of differentiating myoblasts; and (2) CatB is secreted from differentiating myoblasts in an active form at physiological $\mathrm{pH}$. We examined the first prediction using an established method for the staining of surface proteins (Willingham, 1990; Sameni et al., 2000). The second prediction was examined using a continuous assay developed by Linebaugh et al. (1999) for catB activity secreted 'in real time' from living cells, followed by Western blot analysis of differentiating myoblast-conditioned medium to determine the molecular mass form(s) of catB involved.

\section{Cathepsin B is localized on the surface of differentiating myoblasts}

To determine if catB is localized on the surface of differentiating myoblasts, we used an established protocol for the staining of surface proteins that does not permeabilize the cells and permits the differentiation of cell surface catB from lysosomal catB (Sameni et al., 1995) (Figure 6). Using this method, catB was detected as discrete
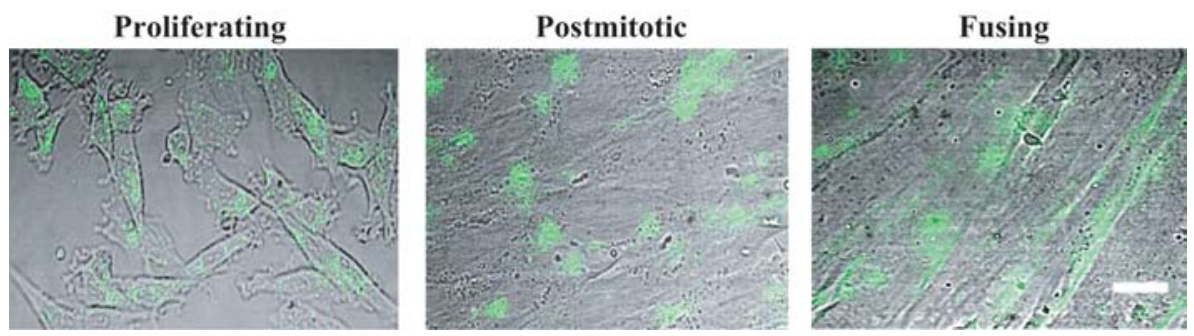

Figure 6 Immunocytochemical localization of cathepsin B on the surface of differentiating myoblasts.

Surface staining of catB was performed on differentiating L6 myoblasts seeded on round glass coverslips at $1 \times 10^{4}$ cells per well of a 24 -well tray grown in $10 \%$ horse serum-supplemented medium. Proliferating, aligning, and fusing myoblasts were fixed and stained for catB protein at $4^{\circ} \mathrm{C}$ using rabbit anti-human liver catB IgG as primary antibody and FITC-conjugated donkey anti-rabbit IgG as secondary antibody (see materials and methods). Cells were observed with a Zeiss LSM 310 microscope in confocal mode at an original magnification of $630 \times$ under oil immersion. For all staining, images are representative of three experiments. Bar: $20 \mu \mathrm{m}$. 


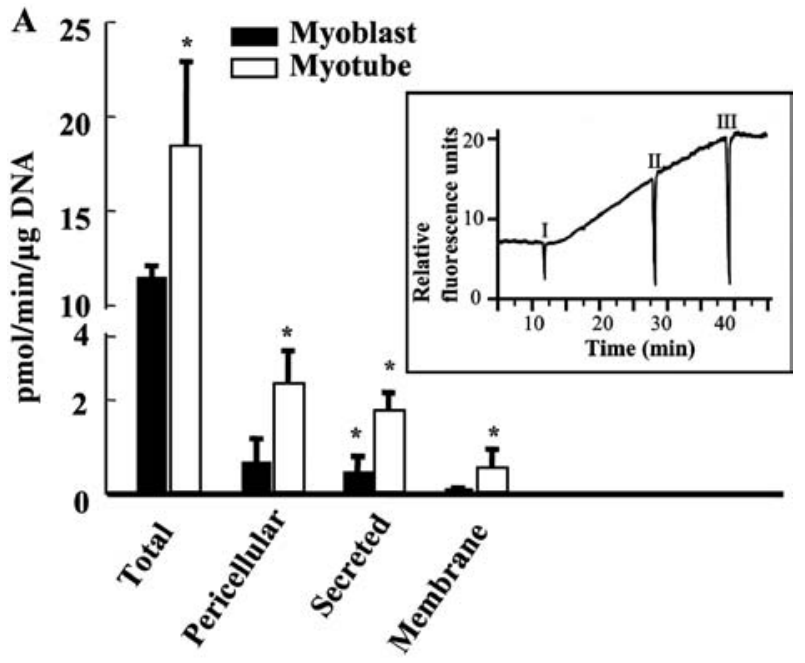

B

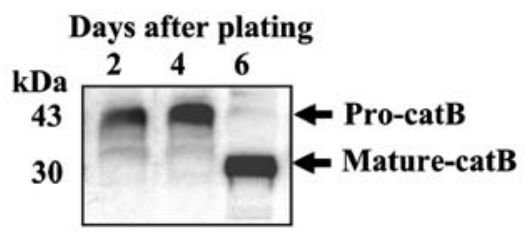

Figure 7 Analyses of pericellular and secreted cathepsin B. (A) Measurement of pericellular and secreted catB activity was performed on living cultures of L6 rat myoblasts grown on $9 \times 9$ $\mathrm{m}^{2}$ glass coverslips. After establishment of a baseline, three coverslips containing monolayer cultures of myoblast (solid bar) or myotube (open bar) populations were added to assay buffer (I) containing Z-Arg-Arg-NHMec substrate and pericellular catB activity was measured continuously for $10-15 \mathrm{~min}$ at $37^{\circ} \mathrm{C}$. Cells were removed (II) and the soluble (secreted) catB activity remaining was monitored for $10 \mathrm{~min}$ at $37^{\circ} \mathrm{C}$. Total catB activity was measured from one $9 \times 9-\mathrm{mm}^{2}$ coverslip by lysing the cells in the presence of $0.1 \%(\mathrm{v} / \mathrm{v})$ Triton $\mathrm{X}-100$ and monitoring catB activity continuously for $10 \mathrm{~min}$ at $37^{\circ} \mathrm{C}$. At the end of each reaction period (III) $10 \mu \mathrm{M}$ CA074 was added and the activity was measured for an additional $5 \mathrm{~min}$ at $37^{\circ} \mathrm{C}$. CatB activity was expressed as $\mathrm{pmol} / \mathrm{min}$ by measuring the slope of the initial velocity curve and was then expressed per $\mu \mathrm{g}$ of DNA. Each value represents the mean of at least three measurements $(n=3)$, with error bars denoting the standard error. Between myoblast and myotube populations, levels of catB activity for total, pericellular and secreted fractions were significantly different $\left({ }^{*} p<0.01\right)$. (B) The molecular mass forms of extracellular secreted catB protein were examined by Western blotting (see materials and methods). Myoblasts were seeded at $3 \times 10^{5}$ cells per $100-\mathrm{mm}$ dish. At proliferating (day 2), postmitotic (day 4), and fusing (day 6) stages of differentiation, conditioned medium was collected and concentrated. Samples were analyzed for catB immunoreactivity using a rabbit polyclonal anti-human catB antibody, HRP-conjugated secondary and enhanced chemiluminescence. Molecular mass standards $(\mathrm{kDa})$ are indicated on the right. After transfer, gels were stained with Coomassie Brilliant Blue and bands corresponding to constitutively expressed proteins were analyzed to ensure equal loading. Immunoblots are representative of at least three experiments.

green patches on the cell surface of differentiating myoblasts in proliferating, postmitotic (aligned) and fusing stages. These results are similar to those reported for catB in human breast carcinoma cells (Sameni et al., 1995) and in U87 human glioma cells (Rempel et al., 1994).

\section{Active cathepsin B is secreted from differentiating myoblasts at $\mathrm{pH} 7.0$}

If catB participates in remodeling of ECM components, catB must be secreted in an active form at physiological $\mathrm{pH}$ (e.g., to activate secreted inactive, high-molecularweight pro-forms of catB and/or to activate other proteases). This prediction was examined directly using a modification of a 'real-time' continuous assay for catB activity optimized for enzyme stability, cell viability and sensitivity (Linebaugh et al., 1999; Jane et al., 2002a). This assay is designed to quantify low levels of active catB secreted from living cells at $\mathrm{pH} 7.0$, and permits the experimenter to distinguish between cell surface and secreted activities. In this assay, levels of pericellular (cell surface and secreted), secreted, and membrane-associated (pericellular minus secreted) catB activities were measured in viable myoblast and myotube populations (Figure 7A). Both pericellular and secreted activities were detected when the catB selective substrate Z-Arg-Arg$\mathrm{NHMec}$ was added directly to myoblast and myotube cultures. In both populations, these activities were several-fold lower than the total activity determined after treatment of cells with Triton X-100. All these activities were completely abolished in the presence of the catB selective inhibitor, CA074. Finally, levels of total, pericellular, secreted and membrane-associated catB activities in the multinucleated myotube population increased by at least $50 \%$ relative to the mononucleated myoblast population.

The molecular mass form of active catB secreted from differentiating L6 myoblasts was examined using immunoblot analysis of samples prepared from conditioned, concentrated medium collected from differentiating myoblasts. In the proliferating and aligning stages of differentiation, a band consistent with the 43-kDa proform of catB protein was detected (Figure 7B, lanes 1 and 2), which is consistent with our previous findings of pro-catB in L6 conditioned myoblast medium fractionated by HPLC. In contrast, a $31-\mathrm{kDa}$ band consistent with the mature form of catB protein was detected in conditioned, concentrated medium of fusing myoblasts (Figure 7B, lane 3) and supports the real-time activity data shown in Figure $7 \mathrm{~A}$.

To the best of our knowledge, this is the first report demonstrating that: (1) catB activity is present on the surface of differentiating $L 6$ rat myoblasts; (2) an active form of catB is secreted from these cells at physiological $\mathrm{pH}$; and (3) the associated activity increases as myoblasts fuse to form myotubes.

\section{Discussion}

There is increasing evidence that the ubiquitous lysosomal cysteine protease, catB, plays a specific role in a number of cellular processes, including the onset of acute pancreatitis (Halengk et al., 2000), the pathogenicity of myoclonus epilepsy (Houseweart et al., 2003), and TNF- $\alpha$-induced hepatocyte apoptosis (Guicciardi et al., 2001). Our in vitro studies suggest that the induction of catB gene expression in differentiating myoblasts involves the MyoD family of skeletal-muscle specific 
transcription factors binding to E-box promoter elements of the catB gene promoter (Jane et al., 2002c), and that the resultant catB activity plays a specific role in myogenesis in vivo, most likely in the events associated with myoblast-myoblast fusion (Jane et al., 2002a,b). While these studies support a role for catB in myogenesis, they tell us little about how and where catB functions during myogenesis. In this study, we provide evidence for the association of active catB with plasma membrane caveolae and the secretion of active catB from differentiating myoblasts at physiological $\mathrm{pH}$ during myoblast fusion.

Myotube formation involves a series of plasma membrane events requiring dramatic structural alterations. Given the catabolic restructuring implicit at the level of the plasma membrane (Thiery et al., 1982), the plasma membrane-cytoskeleton (Moyen et al., 2004), and the plasma membrane-ECM (Rapraeger et al., 1991; Adams and Watt, 1993) of fusing myoblasts, it is reasonable to predict that catB is relocalized from its site of synthesis in proliferating myoblasts to the plasma membrane of fusing myoblasts. Our cell-free fractionation and wholecell immunocytochemical studies support this prediction. For example, results for Triton X-100 sucrose density subcellular fractionation demonstrate that mature cat $B$ is localized to the lysosomal fractions of proliferating myoblasts. In contrast, mature catB is localized to light density fractions containing the plasma membrane marker cav-3 of fusing myoblasts. In fixed whole-cell preparations of fusing myoblasts, catB and cav-3 are co-localized to the cytoplasmic surface of the sarcolemma. Since cav-3 is an integral membrane structural protein specific to membrane caveolae of fusing myoblasts (Lisanti et al., 1994), it follows that a probable trafficking target for catB on the membrane of fusing myoblasts is membrane caveolae. To the best of our knowledge, this is the first direct evidence for the targeting of active catB to plasma membrane caveolae of fusing myoblasts. This evidence has exciting functional implications.

In all cells, caveolae are membrane invaginations reported to play a role in transcytosis, receptor-mediated uptake, stabilization of lipid rafts, and compartmentalization of signaling events at the cell surface (Hazen et al., 2000). It is well established that the principle component of skeletal muscle caveolae, cav-3, plays a role in signal compartmentalization (Lisanti et al., 1994). More recent evidence suggests that cav-3 also plays an important role in the organization and stabilization of the DGC, which in turn serves as a link between laminin in the ECM and the F-actin cytoskeleton (Williams and Lisanti, 1994; Smart et al., 1995).

Our subcellular fractionation studies provide the first evidence of an association of the lysosomal protease catB with both dystrophin and $\beta$-dystroglycan in caveolae of differentiating myoblasts. However, the association of proteolytic enzymes with members of the DG complex is not without precedence and, consequently, functional significance. For example, processing $\beta$-dystroglycan by matrix metalloproteases (MMP) activity disrupts the link between the ECM and the cell membrane via the dystroglycan complex (Yamada et al., 2001). Cav-3 is reported to be a substrate of $\mu$-calpain in $\mathrm{C} 2 \mathrm{C} 12$ mouse myoblasts (Moyen et al., 2004). Calpain-3 is involved in remodeling of cytoskeleton-membrane interactions that include filamin C-sarcoglycan during myoblast fusion and muscle repair (Guyon et al., 2003).

Striking examples of protease involvement in stabilization of the DGC also come from studies of skeletal muscle disease. For example, mutations in the gene encoding the muscle-specific calcium-activated neutral protease 3 (CANP3) large subunit cause limb-girdle muscular dystrophy type 2A (Richard et al., 1995). In sarcoglycanopathy, MMP processing of $\beta$-dystroglycan is activated and is hypothesized to cause the disruption of the link between the basement membrane and sarcolemma (Yamada et al., 2001). Taken together, these studies suggest that skeletal muscle caveolae may serve as organizing centers for proteolytic enzymes that are involved in assembly and stabilization of the DGC during myoblast fusion, regeneration and repair. Our data demonstrating cofractionation of catB with the DGC-associated proteins dystrophin, $\beta$-dystroglycan and cav-3, suggest that catB may be one of these proteases. Indirect support for this association comes from immunohistochemical and subtractive hybridization studies that report twice as much catB protein and mRNA expression in dystrophin-deficient mouse muscles (mdx) than in control muscle (Sano et al., 1988; Fang et al., 2000). While a role for catB at the level of the DGC remains hypothetical, our data provide evidence that catB is associated with multiple members of the DG complex within membrane caveolae.

How is the fully processed $25 / 26-k D a$ active form of catB relocalized to plasma membrane caveolae of fusing myoblasts? Our data support a mechanism involving lysosomal vesicles. First, our fixed-cell immunocytochemical data demonstrate punctate staining of catB in perinuclear vesicles of proliferating myoblasts and vesicles localized to the cytoplasmic face of the plasma membrane of fusing myoblasts. Secondly, our live-cell lysosomal staining with LysoTracker data demonstrates a localization pattern of punctate vesicles that is similar to that of catB staining in fixed whole-cell preparations of differentiating myoblasts. Third, both the 25/26-kDa active form of catB - the form normally found in mature lysosomes (Mach et al., 1992) - and cav-3 - the structural protein of caveolae - are detected in light density Triton-X 100 fractions of fusing myoblasts. A lysosomal vesicle-mediated mechanism for the targeting of catB to membrane caveolae is also supported by the observations of Kuncl et al. (2003). These investigators reported that treatment of differentiating rat myoblasts with the microtubule disrupting agent colchicine induces myopathy characterized by an inhibition of lysosomal trafficking to the sarcolemma and of lysosomal exocytosis. Further studies, including ones using antibodies and inhibitors specific to lysosomal enzyme trafficking proteins, such as mannose-6-phosphate receptors (Szebenyi and Rotwein, 1991), microtubule proteins (Kuncl et al., 2003) and synaptic vesicle-associated proteins (Reddy et al., 2001), are required to gain insight into the mechanisms involved in trafficking catB to plasma membrane caveolae of fusing myoblasts.

If surface-associated catB plays a role in myogenesis, what is/are the mechanism(s) of association with the 
myoblast cell surface? Recent results from tumor cell studies may provide important clues. In tumor cells, caveolae appear to serve as an organization center for the localization of protease receptors, binding proteins and proteases to the cell surface. For example, within caveolae the annexin II tetramer (Allt) forms a putative tumor-cell membrane receptor for procatB at the cell surface (Mai et al., 2000; Sloane et al., 2005). Moreover, other proteases, such as urokinase plasminogen activator (UPA) and its receptor UPAR (Cavallo-Medved et al., 2005) and the matrix metalloproteases MMP-2 and MT1MMP (Annabi et al., 2001; Puyraimond et al., 2001), have been localized to caveolae at the level of the tumor cell surface. Sloane et al. (2005) have hypothesized that interactions of procatB with the annexin II tetramer, through direct binding to $\mathrm{p} 11$, facilitate activation of procatB and in turn tumor progression by initiating a proteolytic cascade involving remodeling proteases. While a putative receptor for catB at the level of the plasma membrane in differentiating myoblasts has not yet been identified, we have used sucrose density fractionation to demonstrate co-fractionation of the 52-kDa isoform of annexin VII with catB in light density plasma membrane fractions of fusing myoblasts. The $47-\mathrm{kDa}$ isoform of annexin $\mathrm{VII}$ is expressed at a basal level throughout proliferating myoblasts and becomes enriched in caveolae as myotubes form. These results are consistent with the possibility of a surface receptor associated with the caveolae of differentiating myoblasts. Nevertheless, binding experiments and screens for catB-associating partners are required to identify the nature of this putative surface receptor.

In addition to extensive cell membrane and membrane-cytoskeleton modifications, myoblast fusion requires dramatic catabolic restructuring at the level of the cell surface and its association with the extracellular environment. If catB plays a role in this restructuring, it is reasonable to predict that at least some active cat $B$ is secreted from the cell surface of differentiating L6 myoblasts. Our results from the 'real-time' activity assay of living L6 myoblasts and immunoblot analysis of conditioned medium support this prediction. These results are also consistent with those obtained from studies in differentiating C2C12 mouse myoblasts (Jane et al., 2002a) and from studies in tumor cells (Linebaugh et al., 1999) that suggest that the mature single-chain $31-\mathrm{kDa}$ form of cat $B$ is the prevalent active form secreted from cells. Moreover, these studies, like our current one, suggest that the $31-\mathrm{kDa}$ form of catB detected in real time is not derived from the secretion and subsequent activation of pro-catB, or from the exocytosis of catB from mature lysosomes. Another compartment, most likely an endosomal compartment, would seem to be involved in the secretion of the single-chain $31-\mathrm{kDa}$ active form of catB.

Based on our current and previous studies, we hypothesize that catB participates in a proteolytic cascade at the level of plasma membrane caveolae that ultimately facilitates the intracellular and/or ECM remodeling necessary for myotube formation. The potential for catB interaction with other proteases at the membrane of fusing myoblasts is substantial and longstanding. For example, the non-lysosomal cysteine protease, m-calpain, increases in a fusion-related manner, exhibits a peripheral distribution in fusion-competent myoblasts (Kaur and Sanwal, 1981; Schollmeyer, 1986), and has been implicated in cleavage of the fibronectin network and myoblast cytoskeletal and membrane components, including caveolin-3 (Dourdin et al., 1999; Moyen et al., 2004), while serine proteases - and their receptors, such as uPA, tissue plasminogen activator (tPA) and the $\alpha$-enolase-type plasminogen receptor (PlgR) - are required for myoblast fusion (Festoff et al., 1986; Lopez-Alemany et al., 2003).

If catB plays a role at the level of the membrane, knowledge of potential substrates should help in the design of screening experiments to identify substrates and/or interacting proteins for catB at the plasma membrane caveolae of fusing myoblasts, and ultimately provide information on the molecular basis for catB function during myogenesis.

\section{Materials and methods}

\section{Materials}

The Micro BCA protein assay kit was purchased from Pierce (Rockford, IL, USA). Xcell II Mini-Cell electrophoresis apparatus, $1.5-\mathrm{mm}$ cassettes, blot modules, nitrocellulose membranes, blotting sponges; combs and filter paper were purchased from Helixx Technologies, Inc. (Scarborough, Canada). Glycine, sodium dodecyl sulfate (SDS), avidin-HRP conjugate, Model 500 power supply and $40 \%$ acrylamide/bis solution were purchased from Bio-Rad Laboratories (Mississauga, Canada). Minimal essential medium ( $\alpha$-MEM), fetal bovine serum, gentamycin sulfate, trypsin, ethylenediaminetetraacetic acid (EDTA), and tissue culture plasticware were purchased from GIBCO (Burlington, Canada). Equine serum was purchased from Hyclone (Logan, UT, USA). Sodium chloride and tissue culture plasticware were purchased from Fisher Scientific (Nepean, Canada). Bovine serum albumin (BSA), Tween, sodium selenite, Giemsa stain, E-64, 7-amino-4-methylcoumarin, creatine phosphate, nicotinamide-adenine dinucleotide (reduced), nicotinamide-adenine dinucleotide phosphate, glucose-6-phosphate dehydrogenase, hexokinase, creatine phosphokinase (CPK), lactate dehydrogenase (LDH), myokinase (MK), cathepsin B (catB), N- $\alpha-C B Z-$ argininyl-argininyl-7-amido methylcoumarin. $\mathrm{HCl}$ (Z-Arg-Arg$\mathrm{NHMec}), \mathrm{N}-\alpha$-CBZ-phenylalanyl L-argininyl-7-amido methylcoumarin $\cdot \mathrm{HCl}$ (Z-Phe-Arg-NHMec) were purchased from Sigma Chemical Co. (St. Louis, MO, USA). The enhanced chemiluminescence Western blotting detection system was purchased from Amersham (Arlington Heights, IL, USA). Sucrose, centrifuge tubes, SW41 Ti rotor, SW 60 rotor and corresponding buckets were purchased from Beckman (Mississauga, Canada). 4Methylumbelliferyl-2-acetamide-2-deoxy- $\beta$-D-glucopyrannoside was purchased from Research Products International Corp. (Mt. Prospect, IL, USA). The catB selective inhibitor, CA074 was purchased from Peptides International, Inc. (Louisville, KY, USA). Rabbit anti-human liver catB IgG was prepared as previously described (Moin et al., 1992). Myosin heavy-chain antibody (MF20) was generously provided by llona Skerjanc (University of Western Ontario, London, ON, Canada). Mouse monoclonal caveolin-3 antibody was purchased from Transduction Laboratories (Lexington, KY, USA). Anti-dystrophin (mAb, clone NCLNLC-DYS3) and anti- $\beta$-dystroglycan (mAb, clone NLC- $\beta-D G$ ) were purchased from Nova Castra (Vector Laboratories, Burlington, Canada). 


\section{Cell cultures}

The fusion-capable (i.e., differentiating) L6 rat myoblast cell line was originally obtained from Bill Sanwal (University of Western Ontario, London, ON, Canada) and first characterized by Dufresne et al. (1976). Cell cultures were maintained at $37^{\circ} \mathrm{C}$ in an atmosphere of $5 \% \mathrm{CO}_{2} / 95 \%$ air in $\alpha$-MEM supplemented with either $10 \%$ horse serum (HS, differentiation conditions) or fetal bovine serum (FBS, proliferation conditions) as previously described (Jane and Dufresne, 1994). Physiological differentiation (i.e., myotube formation) was quantified as the percentage fusion according to established procedures (Jane and Dufresne, 1994).

\section{Cell fractionation}

Cells were plated in $\alpha$-MEM supplemented with $10 \% \mathrm{HS}$ and collected on day 2 (presumptive population), and day 6 (fusing population). Medium was aspirated and the cells were washed twice with cytosol buffer (25 mM HEPES, $125 \mathrm{~mm}$ potassium acetate, $2.5 \mathrm{~mm}$ magnesium acetate, $200 \mathrm{~mm}$ sucrose, $1 \mathrm{~mm}$ DTT, adjusted to $\mathrm{pH} 7.0$ ). Cells were then swelled in a 10-fold dilution of cytosol buffer for $10 \mathrm{~min}$ and then collected using a rubber policeman. Cells were homogenized using a Dounce type $\mathrm{B}$ homogenizer. Samples were then centrifuged at $1000 \mathrm{~g}$ for 10 min in an IEC Micromax centrifuge. Pellets, corresponding to unbroken cells and intact nuclei, were frozen at $-20^{\circ} \mathrm{C}$. The supernatant was then removed and either centrifuged at $10000 \mathrm{~g}$ for $10 \mathrm{~min}$ to obtain crude lysosomes (pellet diluted into cytosol buffer) or centrifuged at $250000 \mathrm{~g}$ for $15 \mathrm{~min}$ in a SW60 rotor using an L8-M Beckman ultracentrifuge to obtain crude cytosol (supernatant) and crude membrane (pellet). All samples were stored at $-20^{\circ} \mathrm{C}$ and later analyzed for catB protein using SDS-PAGE and Western blotting.

\section{Sucrose density fractionation}

Preparation of caveolae-enriched membrane fractions was essentially performed as previously described (Song et al., 1996). Cells were plated at $3 \times 10^{5}$ cells per $100-\mathrm{mm}$ tissue culture dish in $\alpha$-MEM supplemented with $10 \%$ HS. On days 2 (proliferating) and 6 (fusing) of differentiation, plated cells were washed twice with MES buffer and then collected on an ethanoldry ice bath in $750 \mu \mathrm{l}$ of MES buffer containing 1\% Triton X100. Cells were homogenized by eight passages through a 20G needle. For each sample, $1.6 \mathrm{ml}$ was loaded to the bottom of a $14 \mathrm{~mm} \times 89 \mathrm{~mm}$ Beckman centrifuge tube and $2.4 \mathrm{ml}$ of a $67 \%$ sucrose solution was then added to make $4 \mathrm{ml}$ of a $40 \%$ sucrose solution. For each sample, $4 \mathrm{ml}$ of a $30 \%$ sucrose solution was layered on top of the $40 \%$ layer using a syringe with a 21 -gauge needle, and $4 \mathrm{ml}$ of $5 \%$ sucrose was layered to the top of the $30 \%$ solution. All samples were then centrifuged at $185000 \mathrm{~g}$ in a SW41 Ti rotor in an L8-M Ultracentrifuge for $20 \mathrm{~h}$ at $4^{\circ} \mathrm{C}$. A total of $121-\mathrm{ml}$ fractions were collected, beginning at the top of the gradient. Each fraction was diluted in cold MES buffer to a total of $12 \mathrm{ml}$ and then centrifuged at $176000 \mathrm{~g}$ for $70 \mathrm{~min}$ in a SW41 Ti rotor in an L8-M Ultracentrifuge. The supernatants were decanted and the pellets were resuspended in $40 \mu \mathrm{l}$ of $2 \times$ sample buffer containing $10 \% \beta$-mercaptoethanol. Equal-volume aliquots from each gradient fraction were analyzed by SDS-PAGE and Western blotting.

\section{Enzyme activity analysis}

Intracellular cathepsin B Cell homogenates were prepared from cells collected every $24 \mathrm{~h}$ from day 2 of growth to day 6 as previously described (Jane and Dufresne, 1994). CatB activity was measured using $20 \mathrm{~mm}$ of the catB-selective fluorimetric substrate, Z-Arg-Arg-NHMec according to a modified procedure of Jane and Dufresne (1994). A 500- $\mu$ l aliquot of cell homogenate $(10.0 \mu \mathrm{g}$ of protein diluted in $0.1 \%$ Brij 35 solution) was pre-incubated for $5 \mathrm{~min}$ at $37^{\circ} \mathrm{C}$ with $250 \mu$ l of activation buffer (352 $\mathrm{mM} \mathrm{KH}_{2} \mathrm{PO}_{4}, 48 \mathrm{mM} \mathrm{Na}_{2} \mathrm{HPO}_{4}, 4 \mathrm{~mm}$ disodium EDTA, and $8 \mathrm{~mm}$ DTT, pH 6.0). The reaction was initiated with the addition of $250 \mu \mathrm{l}$ of substrate. The specificity of the substrate was checked by adding $10^{-6} \mathrm{M}$ of the catB selective inhibitor CA074, or of the cysteine protease inhibitor E-64 (Towatari et al., 1991). The fluorescence of free aminomethylcoumarin in each reaction tube was measured at an excitation wavelength of $370 \mathrm{~nm}$ and an emission wavelength of $460 \mathrm{~nm}$. One milliunit of proteolytic activity was defined as the quantity of enzyme releasing $1 \mathrm{nmol}$ of aminomethylcoumarin per min.

Creatine phosphokinase The activity of the muscle-specific biochemical enzyme marker, creatine phosphokinase was measured according to established procedures (Jane et al., 2002a).

Pericellular cathepsin B Pericellular and secreted catB activity produced by cells growing on coverslips was measured using a continuous assay according to the established procedure of Linebaugh et al. (1999) and modified by Jane et al. (2002a). Cells growing on $9 \times 9-\mathrm{mm}^{2}$ glass coverslips were rinsed twice in PBS, placed in coverslip holders and equilibrated in assay buffer (Hank's balanced-salt solution supplemented with $0.6 \mathrm{mM} \mathrm{CaCl}_{2}, 0.6 \mathrm{~mm} \mathrm{MgCl}_{2}, 2 \mathrm{~mm}$ L-cysteine and $25 \mathrm{~mm}$ Pipes, adjusted to $\mathrm{pH} 7.0$ ) minus substrate at $37^{\circ} \mathrm{C}$ for $5 \mathrm{~min}$. The rate of fluorescent product formation was recorded in a Shimadzu RF-450 spectrophotometer set at $380 \mathrm{~nm}$ for excitation and $460 \mathrm{~nm}$ for emission, and equipped with a temperature-controlled cuvette holder, a microstirrer and a DR-3 data chart recorder. Recordings generally consisted of four readings: (i) a fluorescent baseline for the assay buffer containing $100 \mu \mathrm{M} Z$ Arg-Arg-NHMec substrate (5 min); (ii) the rate of fluorescent product formation due to the introduction of cells, i.e., pericellular catB activity; (iii) the rate of fluorescent product formation after the removal of cells from the cuvette, i.e., secreted catB activity (10 min); and (iv) the rate of fluorescent product formation after the addition of CA074 (10 $\mu \mathrm{M}$ final concentration). Activity was expressed as $\mu \mathrm{U} / \mu \mathrm{g}$ of DNA. DNA levels were determined by the procedure of Downs and Wilfinger (1983) using bisbenzimide dye (H33258) and calf thymus DNA standard.

\section{SDS-PAGE and immunoblot analysis}

Cell homogenates were prepared from cells collected every $24 \mathrm{~h}$ on days 2-6 of growth (Jane and Dufresne, 1994) with the following modifications. Cells were harvested in PBS supplemented with $0.5 \mu \mathrm{M}$ ALLN, $1 \mathrm{mM}$ PMSF and $100 \mathrm{U} / \mathrm{ml}$ aprotinin. Clarified cell homogenates were snap-frozen in liquid nitrogen and stored in an Ultra Low freezer at $-80^{\circ} \mathrm{C}$. The total protein concentration of each homogenate was measured using the Micro BCA protein assay reagent kit. Samples of $40 \mu \mathrm{g}$ (for myosin heavy chain, MHC) or $10 \mu \mathrm{g}$ (for catB) of cell lysate were separated on a $7.5-12 \%$ SDS-polyacrylamide gel. For cell fractionation studies, $30-\mu \mathrm{l}$ aliquots were loaded onto each lane. After transfer to nitrocellulose membranes, blots were probed with primary antibodies against MHC (1:200), catB (1:5000), cav3 (1:5000), annexin VII (1:2000), dystrophin (1:1000), $\beta$-dystroglycan (1:1000) and secondary antibodies conjugated with horseradish peroxidase $(1: 10000)$ in TBS wash buffer $(20 \mathrm{mM}$ Tris, $\mathrm{pH} 7.5,0.5 \mathrm{M} \mathrm{NaCl}$ ) containing $0.5 \%$ Tween 20 and $5 \%$ (w/v) non-fat dry milk. After washing, specifically bound antibodies were detected by enhanced chemiluminescence according to the manufacturer's instructions. Quantification and analysis of the bands were performed using a Luminescent 
Image Analyzer LAS-1000 Plus (Fujifilm) and expressed as AU/ $\mathrm{mm}^{2}$.

\section{Immunocytochemical staining and confocal microscopy}

Cells were seeded onto glass coverslips in differentiation medium and were used during proliferation (day 2), postmitotic (day 4) and fusing (day 6) stages of differentiation for intracellular or surface staining as previously described (Sameni et al., 1995). Intracellular staining was carried out at room temperature using saponin-permeablized cells, whereas surface staining was carried out at $4^{\circ} \mathrm{C}$ using unpermeabilized cells. Rabbit anti-human liver catB and goat anti-mouse cav-3 were used as primary antibodies. Fluorescein-conjugated affinity-purified donkey anti-rabbit, fluorescein-conjugated affinity-purified donkey anti-goat and Texas red-conjugated affinity-purified donkey anti-goat were used as secondary antibodies. Coverslips were mounted upside-down with Slow-Fade antifade reagent on glass slides and the cells were observed using a Zeiss LSM 310 microscope in confocal mode.

\section{Lysosomal staining of living cells}

L6 myoblasts were plated at $4 \times 10^{4}$ cells per $30-\mathrm{mm}$ tissue culture dish (containing two glass coverslips) in $\alpha$-MEM supplemented with $10 \% \mathrm{HS}$. Live cell populations were observed in proliferation (day 2), postmitotic (day 4) and fusing (day 6) stages of differentiation. A 2- $\mu$ l aliquot of LysoTracker was added to $20 \mathrm{ml}$ of serum free $\alpha-M E M$. Cells were then washed twice with HBSS, incubated at $37^{\circ} \mathrm{C}$ in LysoTracker-containing medium for $2.5 \mathrm{~h}$, washed twice with HBSS, incubated again at $37^{\circ} \mathrm{C}$ in LysoTracker-free medium containing $10 \% \mathrm{HS}$ for $1 \mathrm{~h}$, and washed three times with HBSS. Washed cells were observed immediately using a Bio-Rad confocal microscope and captured images were merged using Confocal Assistant computer software.

\section{Protein determination}

Protein levels were determined by the method of Bradford (1976) and by the Pierce Micro BCA assay.

\section{Degree of reproducibility}

Calculations of standard deviations, standard errors and statistical tests, including Student's $t$-test, were computer-generated using Sigmaplot.

\section{Acknowledgments}

This study was supported by a Discovery Grant to Michael J. Dufresne from the Natural Sciences and Engineering Research Council (NSERC) of Canada, and by a grant to Bonnie F. Sloane from the National Cancer Institute (USA) (CA36481).

\section{References}

Adams, J. and Watt, F. (1993). Regulation of development and differentiation by the extracellular matrix. Development 117 , 1183-1198.

Annabi, B., Lachambre, M., Bousquet-Gagnon, N., Page, M., Gingras, D. and Beliveau, R. (2001). Localization of membrane-type 1 matrix metalloproteinase in caveolae membrane domains. Biochem. J. 353, 547-553.
Anderson, R.G.W. (1998). The caveolae membrane system. Annu. Rev. Biochem. 67, 199-225.

Berquin, I. and Sloane, F. (1996). Cathepsin B expression in human tumors. In: Intracellular Protein Catabolism (New York, USA: Plenum Press), pp. 281-293.

Biederer, C.H., Riess, S.J., Moser, M., Florio, M., Isreal, M.A., McCormick, F., and Buettner, R. (2000). The basic-helix-loophelix transcription factors myogenin and Id2 mediate specific induction of caveolin-3 gene expression during embryonic development. J. Biol. Chem. 275, 26245-26251.

Bird, J.W., Roisen, F., Yorke, G., Lee, J., McElligott, M., Triemer, D., and St. John, A. (1981). Lysosomes and proteolytic activity in cultured striated muscle cells. J. Histochem. Cytochem. 29, 431-439.

Blake, D.J., Weir, A., Newey, E., and Davies, K.E. (2002). Function and genetics of dystrophin-related proteins in muscle. Physiol. Rev. 82, 291-329.

Bradford, M. (1976). A rapid and sensitive method for the quantification of microgram quantities of protein using the principle of dye binding. Anal. Biochem. 72, 248-254.

Cavallo-Medved, D., Dosescu, J., Linebaugh, B.E., Sameni, M., Rudy, D., and Sloane, B.F. (2003). Mutant K-ras regulates cathepsin B localization on the surface of human colorectal carcinoma cells. Neoplasia 5, 507-519.

Cavallo-Medved, D., Mai, J., Dosescu, J., Sameni, M., and Sloane, B.F. (2005). Caveolin-1 mediates the expression and localization of cathepsin B, pro-urokinase plasminogen activator and their cell-surface receptors in human colorectal carcinoma cells. J. Cell Sci. 118, 1493-1503.

Clemen, C.S., Hofmann, A., Zamparelli, C., and Noegel, A.A. (1999). Expression and localisation of annexin VII (synexin) isoforms in differentiating myoblasts. J. Muscle Res. Cell Motil. 7, 699-679.

Dourdin, N., Balcerzak, D., Brustis, J., Poussard, S., Cottin, P., and Ducastaing, A. (1999). Potential m-calpain substrates during myoblast fusion. Exp. Cell Res. 246, 433-442.

Downs, T.R. and Wilfinger, W.W. (1983). Fluorometric quantification of DNA in cells and tissue. Anim. Biochem. 131, 538-547.

Dufresne, M.J., Rogers, J, Coulter, M.B., Bal, E., Lo, T., and Sanwal, B.D. (1976). Apparent dominance of serine auxotrophy and the absence of expression of muscle-specific proteins in rat myoblast X mouse L-cell hybrids. Somatic Cell Genet. 2, 521-535.

Fang, J., Shi, G., and Vaghy, P.L. (2000). Identification of the increased expression of monocyte chemoattractant protein1, cathepsin S, UPIX-1, and other genes in dystrophin-deficient mouse muscles by suppression subtractive hybridization. J. Cell Biochem. 79, 164-172.

Festoff, B., Hantai, D., Soria, J., Thomaidis, A., and Soria, C. (1986). Plasminogen activator in mammalian skeletal muscle: characteristics of effect of denervation on urokinase-l like and tissue activator. J. Cell Biol. 103, 1415-1421.

Gogos, J., Thompson, R., Lowery, W., Sloane, B., and Weintraub, H. (1996). Regulation of lysosomal protease cathepsin $\mathrm{B}$ in skeletal muscle growth and fusion. J. Cell Biol. 134, 1-12.

Gong, Q., Chan, S.J., Bajkowski, A.S., Steiner, D.F., and Frankfater, A. (1993) Characterization of the cathepsin B gene and multiple mRNAs in human tissues: evidence for alternative splicing of cathepsin B pre-mRNA. DNA Cell Biol. 12, 299-309.

Guerin, C.W. and Holland, P. (1995). Synthesis and secretion of matrix-degrading metalloproteases by human skeletal muscle satellite cells. Dev. Dynamics 202, 91-99.

Guicciardi, M.E., Miyoshi, H., Bronk, S.F., and Gores, G.J. (2001). Cathepsin B knockout mice are resistant to tumor necrosis factor- $\alpha$-mediated hepatocyte apoptosis and liver injury: implications for therapeutic applications. Am. J. Pathol. 159, 2045-2054. 
Guyon, J., Kudryashova, E., Potts, A., Dalkilic, I., Brosius, M., Thompson, T., Beckmann, J., Kunkel, L., and Spencer, M. (2003). Calpain 3 cleaves filamin $C$ and regulates its ability to interact with $\gamma$ - and $\delta$-sarcoglycan. Muscle Nerve 28, 472-483.

Halengk, W., Lerch, M.M., Brandt-Nedelev, B., Roth, W., Ruthenburger, M., Reinheckel, T., Domschke, W., Lippert, H., Peters, C., and Deussing, J. (2000). Role of cathepsin B in intracellular trypsinogen activation and the onset of acute pancreatitis. J. Clin. Invest. 106, 773-781.

Hazen, L.G., Bleeker, F.E., Lauritzen, B., Bahns, S., Song, J., Jonker, A., Van Driel, B.E., Lyon, H., Hansen, U., Kohler, A., and van Noorden, C.J. (2000). Comparative localization of cathepsin B protein and activity in colorectal cancer. J. Histochem. Cytochem. 48, 1421-1430.

Houseweart, M.K., Pennacchio, L.A., Vilaythong, A., Peter, C., Noebels, J.L., and Myers, R.M. (2003). Cathepsin B but not cathepsins $\mathrm{L}$ or $\mathrm{S}$ contributes to the pathogenesis of Unverricht-Lundborg progressive myoclonus epilepsy (EPM1). J. Neurobiol. 56, 315-327.

Jane, D.T. and Dufresne, M.J. (1994). Expression and regulation of three lysosomal cysteine protease activities during growth of a differentiating L6 rat myoblast cell line and its non-fusing variant. Biochem. Cell. Biol. 72, 267-274.

Jane, D.T., DaSilva, L., Koblinski, J., Horwitz, H., Sloane, B.F., and Dufresne, M.J. (2002a). Evidence for the involvement of cathepsin B in skeletal muscle cell differentiation. J. Cell. Biochem. 84, 520-531.

Jane, D.T., Morvay, L.C., Allen, F., Sloane, B.F., and Dufresne, M.J. (2002b). Selective inhibition of cathepsin B with cellpermeable CA074Me negatively affects L6 rat myoblast differentiation. Biochem. Cell Biol. 80, 1-9.

Jane, D.T., Morvay, L.C., Koblinski, J., Yan, S., Saad, F.A., Sloane, B.F., and Dufresne, M.J. (2002c). Evidence that Ebox promoter elements and MyoD transcription factors play a role in the induction of cathepsin $\mathrm{B}$ gene expression during human myoblast differentiation. Biol. Chem. 383, 1833-1844.

Kaur, H. and Sanwal, B.D. (1981). Regulation of the activity of calcium activated neutral protease during differentiation of skeletal myoblasts. Can. J. Biochem. 59, 743-747.

Knudsen, K.A. and Horwitz, A.F. (1977). Tandem events in myoblast fusion. Dev. Biol. 58, 328-338.

Kuncl, R., Bilak, M., Craig, S., and Adams, R. (2003). Exocytotic 'constipation' is a mechanism of tubulin/lysosomal interaction in colchicine myopathy. Exp. Cell Res. 285, 196-207.

Linebaugh, B., Sammeni, M., Day, N., Sloane, B.F., and Keppler, D. (1999). Exocytosis of active cathepsin B. Eur. J. Biochem. 264, 100-109.

Lisanti, M.P., Sherer, P.E., Vidugiriene, J., Tang, Z., Hermanowski-Vosatka, A., Tu, Y.H., Cook, R.F., and Sargiacomo, M. (1994). Characterization of caveolin-rich membrane domains isolated from an endothelial-rich source: implications for human disease. J. Cell Biol. 126, 111-126.

Lopez-Alemany, R., Suelves, M., and Munoz-Canoves, P. (2003). Plasmin generation dependent on alpha-enolase-type plamsminogen receptor is required for myogenesis. Thromb. Haemost. 90, 724-733.

Mach, L., Stuwe, K., Hagen, A., Ballaum, C., and Glossl, J. (1992). Proteolytic processing and glycosylation of cathepsin B. The role of the primary structure of the latent precursor and the carbohydrate moiety for cell-type-specific molecular forms of the enzyme. Biochem. J. 282, 577-582.

Mai, J., Finley, R.L., Waisman, D.M., and Sloane, B.F. (2000). Human procathepsin B interacts with the annexin II tetramer on the surface of tumor cells. J. Biol. Chem. 275, 12806-12812.

Meacci, E., Donati, C., Cencetti, F., Romiti, E., Farnararo, M., and Bruni, P. (2000). Receptor-activated phospholipase D is present in caveolin-3-enriched light membranes of $\mathrm{C} 2 \mathrm{C} 12$ myotubes. FEBS Lett. 473, 10-14.
Moin, K., Day, N.A., Sameni, M., Hasnain, S., Hirama, T., and Sloane, B.F. (1992). Human tumour cathepsin B. Comparison with normal liver cathepsin B. Biochem. J. 285, 427-434.

Moyen, C., Goudenege, S., Poussard, S., Sassi, A., Brustis, J., and Cottin, P. (2004). Involvement of $\mu$-calpain (CAPN 1) in muscle cell differentiation. Int. J. Biochem. Cell Biol. 36, 728-743.

Olson, E.N. (1990). MyoD family: a paradigm for development? Genes Dev. 4, 1454-1461.

Puyraimond, A., Fridman, R., Lemesle, M., Arbeille, B., and Menashi, S. (2001). MMP-2 colocalizes with caveolae on the surface of endothelial cells. Exp. Cell Res. 262, 28-36.

Radojevic, V., Lin, S., and Burgunder, J.M. (2000). Differential expression of dystrophin, utrophin, and dystrophin-associated proteins in human muscle culture. Cell Tissue Res. 300, 447-457.

Rapraeger, A., Krufka, A., and Olwin, B. (1991). Requirement of heparan sulfate for bFGF-mediated fibroblast growth and myoblast differentiation. Science 21, 1705-1708.

Reddy, A., Caler, E., and Andrews, W. (2001). Plasma membrane repair is mediated by $\mathrm{Ca}^{2+}$-regulated exocytosis of lysosomes. Cell 106, 157-169.

Rempel, S.A., Rosenblum, M.L., Mikkelsen, T., Yan, P.S., Ellis, K.D., Golembieski, W.A., Sameni, M., Rozhin, J., Ziegler, G., and Sloane, B.F. (1994). Cathepsin B expression and localization in glioma progression and invasion. Cancer Res. 54, $6027-6031$.

Richard, I., Broux, O., Allamand, V., Fougerousse, F., Chiannikulchai, N., Bourg, N., Brenguier, L., Devaud, C., Pasturaud, P., and Roudaut, C. (1995). Mutations in proteolytic enzyme calpain-3 cause limb-girdle muscular dystrophy type 2A. Cell $81,27-40$

Rieger, F., Grument, M., and Edelman, G.M. (1985). N-CAM and the vertebrate neuromuscular junction. Cell Biol. 101, 285-293.

Sameni, M., Elliott, E., Ziegler, G., Fortgens, P., Dennison, C., and Sloane, B.F. (1995). Cathepsins B and D are localized at the surface of human breast cancer cells. Pathol. Oncol. Res. 1, 43-53.

Sameni, M., Moin, K., and Sloane, B.F. (2000). Imaging proteolysis by living human breast cancer cells. Neoplasia 6 , 496-504.

Sano, M., Wada, Y., li, K., Kominami, E., Katunuma, N., and Tsukagoshi, H. (1988). Immunolocalization of cathepsins B, H and $\mathrm{L}$ in skeletal muscle of $\mathrm{X}$-linked muscular dystrophy (mdx) mouse. Acta Neuropathol. (Berl.) 75, 217-225.

Schollmeyer, J. (1986). Possible role of calpain I and calpain II in differentiating muscle. Exp. Cell Res. 163, 413-422.

Sloane, B.B., Yan, S., Podgorski, I., Linebaugh, B, Cher, M., Mai, J., Cavallo-Medved, D., Sameni, M., Dosescu, J., and Moin, K. (2005). Cathepsin B and tumor proteolysis: contribution of the tumor microenvironment. Sem. Cancer Biol. 15, 149-157.

Smart, E.J., Ying, Y.S., Mineo, C., and Anderson, R.G. (1995). A detergent-free method for purifying caveolae membrane from tissue culture cells. Proc. Natl. Acad. Sci. USA 92, 10104-10108.

Song, K.S., Scherer, P.E., Tang, Z., Okamoto, T., Li, S., Chafel, M., Chu, C., Kohtz, D.S., and Lisanti, M.P. (1996). Expression of caveolin-3 in skeletal, cardiac, and smooth muscle cells. Caveolin-3 is a component of the sarcolemma and co-fractionates with dystrophin and dystrophin-associated glycoproteins. J. Biol. Chem. 271, 15160-15165.

Stockdale, F.E. (1992). Myogenic cell lineages. Dev. Biol. 154, 284-294.

Szebenyi, G., and Rotwein, P. (1991). Differential regulation of mannose 6-phosphate receptors and their ligands during the myogenic development of C2 cells. J. Biol. Chem. 266, 5534-5539.

Thiery, J., Duband, J., Rutishaurer, U., and Edelman, G. (1982). Cell adhesion molecules in early chicken embryogenesis. Proc. Natl. Acad. Sci. USA 79, 6737-6741. 
Towatari, T., Nikawa, T., Murata, M., Yokoo, C., Tamai, M., Hanada, K., and Katanuma, M. (1991). Novel epoxysuccinyl peptides; a selective inhibitor of cathepsin B in vivo. FEBS Lett. 280, 311-315.

Williams, T.M. and Lisanti, M.P. (2004). The caveolin proteins. Ann. Med. 36, 584-595.

Willingham, M.C. (1990). Imunocytochemical methods: useful and informative tools for screening hybridomas and evaluating antigen expression. Focus 12, 62-71.

Yamada, H., Saito, F., Fukuta-Ohi, H., Zhong, D., Hase, A., Arai,
K., Aouyama, A., Maekawa, R., Shimizu, T., and Matsumura, K. (2001). Processing of $\beta$-dystroglycan by matrix metalloprotease disrupts the link between the extracellular matrix and cell membrane via the dystroglycan complex. Hum. Mol. Genet. 15, 1563-1569.

Yeoh, G. and Holtzer, H. (1977). The effects of cell density, conditioned medium and cytosine arabinoside in myogenesis in primary and secondary cultures. Exp. Cell Res. 104, 63-78.

Received August 15, 2005; accepted November 30, 2005 
Copyright of Biological Chemistry is the property of Walter de Gruyter GmbH \& Co. KG. and its content may not be copied or emailed to multiple sites or posted to a listserv without the copyright holder's express written permission. However, users may print, download, or email articles for individual use. 